\title{
A visão de professores de física do ensino médio sobre o papel de museus e centros de ciências na aprendizagem de conceitos científicos
}

\author{
High school physics teachers vision about the role of museums and science centers \\ on the apprenticeship of scientific concepts
}

\author{
Daniela de Andrade Santos ${ }^{1}$ e Marco Aurélio Alvarenga Monteiro ${ }^{2}$ \\ ${ }^{1}$ Universidade Federal de Itajubá \\ daniela.andrade31@gmail.com \\ ${ }^{2}$ Faculdade de Engenharia de Guaratinguetá - Unesp \\ marco.aurelio.feg@gmail.com
}

\begin{abstract}
Resumo
Este trabalho buscou ouvir a opinião de professores de Física sobre a contribuição das atividades educativas realizadas em museus e centros de ciências para o processo de ensino e de aprendizagem dos alunos. Para isso, solicitamos que os professores respondessem a um questionário aberto e estruturado com dezesseis perguntas cujo objetivo era compreender como o docente entende o estabelecimento de uma parceria entre a escola e o museu de ciências e qual sua opinião sobre a importância dessa iniciativa. Os resultados mostraram que os professores reconhecem a importância das atividades experimentais para a aprendizagem, mas, apesar disso, as utilizam com pouca frequência em sala de aula. Sendo assim, destacam a importância das atividades realizadas pelos museus de ciências, tendo em vista seu caráter motivador e complementar à educação formal. Os docentes participantes mostraram-se dispostos a participar de ações que visam o estabelecimento de uma parceria entre o centro de ciência e a escola, porém, a grande maioria dos participantes da pesquisa, não soube dizer como poderia se estabelecer, metodologicamente, essa parceria.
\end{abstract}

Palavras-chave: Ensino não formal; Museus de ciências; relação museu escola.

\begin{abstract}
This work heard the opinion of physics teachers about the contribution of the educational activities realized in museums and science centers for the process of teaching and learning of the students. To reach this, we asked the teachers to answer to an open and structured questionnaire with sixteen questions, which had the objectives of comprehending how the instructor understands the establishment of a partnership between the school and the science museum and what is his opinion about the importance of this initiative. The results show that the teachers recognize the importance of the experimental activities for the learning process; however, they use them with low frequency in classroom. Thus, they highlight the importance of the activities realized by the science museums, owing to its motivational and complementary role in the formal education. The interviewed teachers showed themselves willing to participate in actions that aim the establishment of a partnership between the science center and the school, however, the majority of the participants in the research could not propose how this partnership could be established, methodologically.
\end{abstract}

Keywords: Non-formal education; science museums; museum school relationship. 


\section{Introdução}

Considerando que a sociedade em que vivemos foi e vem sendo construída com base na Ciência e na Tecnologia, é fundamental para o exercício da cidadania crítica um conhecimento, não apenas sobre conceitos científicos, mas também sobre a natureza da Ciência, do fazer científico e sobre os impactos do desenvolvimento científico e tecnológico sobre a sociedade.

Nesse sentido, instituições de ensino não formal, como os museus e centros de ciências, são consideradas por muitos como importantes aliadas para se promover a alfabetização científica da população (SCHALL, 2002; MARANDINO, 2001; VIEIRA et.al., 2005; VOGT, 2011).

Para Santos (2015) as pesquisas que normalmente são realizadas sobre o aprendizado nessas instituições não mede a principal contribuição dos museus e centros de ciências: o aumento do repertório cultural de palavras, termos e conceitos que, se não são bem compreendidos nas visitas, servirão como base conceitual para futuros aprimoramentos de compreensão. Nessa linha de raciocínio, a autora defende que esse aprimoramento seja feito na escola, instituição de educação formal que pode e deve interagir com as instituições de educação não formal para efetivar o processo de aprendizagem de conceitos científicos.

Assim sendo, para Santos (opus cit.), os museus de ciências, apesar de estarem tão naturalmente ligados ao ensino formal, não possuem como função primordial promover a aprendizagem formal de conceitos científicos, tal como defendem Valente et. al. (2005), Schall (2002) e Marandino (2001) os museus de ciências têm como função principal a ampliação da cultura científica e tecnológica dos cidadãos, a partir de uma abordagem lúdica, informando e, ao mesmo tempo, promovendo entretenimento aos visitantes.

Essas instituições possuem uma forma particular de envolver o público com o conhecimento científico, sendo assim, "através de variados estímulos oferecidos ao público, diferentes daqueles da escola, o processo de aquisição do conhecimento se torna particular nesses espaços" (MARANDINO, 2001, p. 93).

Sobre os aspectos positivos da aprendizagem em museus de ciências, Almeida (1997) destaca o ganho afetivo que as visitas nesses espaços podem proporcionar aos seus visitantes. De acordo com a autora, uma atividade de visitação pode gerar ganhos cognitivos e afetivos, porém, esses últimos se sobressaem devido à motivação e ao estímulo da curiosidade que estes espaços podem proporcionar.

Vieira et.al (2005) afirmam que, além de promover a motivação e atiçar a curiosidade, as ações educativas promovidas nos museus e centros de ciências podem contribuir com a escola em seu processo de ensino formal de conceitos científicos. As autoras indicam que, se bem dirigidas, as atividades realizadas em espaços não formais podem ser boas aliadas das aulas formais, isso porque longe de privilegiarem a memorização de informações, a discussão de conceitos, ideias e princípios científicos, realizadas nos museus e centros de ciências, podem ser feitas de modo a agregar bagagem cognitiva aos visitantes, pelo processo dinâmico de contextualização.

Nessa mesma linha de pensamento, Vogt (2011), entende que os museus têm o potencial para alfabetizar cientificamente o cidadão, pois pode divulgar conceitos científicos que se aplicam no cotidiano das pessoas, levando os visitantes a uma reflexão sobre os impactos sociais que a Ciência e a Tecnologia geram. Assim sendo é possível falar em educação para a criticidade e para a autonomia do cidadão, pois que, apesar de iniciar a abordagem dos conceitos científicos no dia-a-dia das pessoas, não se limita a ela, ao contrário, pode ampliar as discussões para se pensar o mundo, contribuindo para tornar ilimitada a percepção da realidade.

Gaspar (1993) e Vieira et.al (2005) afirmam que os museus e os centros de ciências acabam por oferecer aos visitantes experiências que a escola não foi capaz de oferecer, como a realização de atividades experimentais e a apresentação de recursos audiovisuais que facilitam e complementam a aprendizagem de conceitos.

Contudo, como destacam Rennie e Williams (2002), os museus e centros de ciências também têm seus críticos. Os autores citam a crítica de Champagne (1975), que reiterada por Fara (1994), Parkyn (1993) e Ravest (1993), afirmam que a dimensão do entretenimento considerada nessas instituições obscurece a dimensão do aprendizado científico. Para Rennie e Williams (2002), essa crítica somada a outras, como as de Shortland (1987) e Wymer (1991), que entendiam as atividades nos museus e centros de ciências como ações que distorcem a natureza da Ciência, não foram devidamente refutadas.

Tais críticas reforçam o ponto de vista de que, ao mesmo tempo em que o museu, como instituição de educação não formal, deve ir além de se constituir em simples espaço de contemplação, as escolas e os educadores devem ser capazes de preparar os alunos para explorarem todo o potencial que o museu pode oferecer. Nesse caso, instrumentalizar os alunos para que façam uma leitura detalhada e crítica das exposições museológicas é fundamental.

Em acordo com essa afirmação, Gohn (2010), acredita que a articulação entre espaços não formais com a escola pode trazer significativa contribuição para a educação científica do cidadão. Contudo, Marandino (2001) ressalta que estes espaços de ensino não podem ser vistos como simples complementos da educação formal. Para a autora, enxerga-los dessa forma pode levar à chamada escolarização dos museus de ciências e, dessa forma, trazer prejuízos à relação museu-escola.

Lopes (1991) trata da questão da escolarização dos museus de ciências. A autora concorda com a contribuição dos espaços de ensino não formal para o ensino formal, no entanto há um problema em buscar no museu somente uma forma de enriquecer os currículos ou buscar nessas exposições um meio de ilustrar os conceitos científicos. 
Para a autora, a escolarização é "o processo de incorporação pelos museus das finalidades e métodos do ensino escolar" (LOPES, 1991, p. 449), esse processo caracterizase por impor aos alunos atividades metodologicamente iguais as da escola, tais como fazer anotações, relatórios de visita, avaliações de aprendizagem, enfim, atividades que levam o aluno a se portar como se estivesse na escola.

Marandino (2001) destaca outro fato que pode contribuir com o processo de escolarização dos museus: a questão dessas instituições utilizarem os saberes de referência da escola para o desenvolvimento de suas atividades, afinal, grande parte do público dos museus de ciências provém das excursões escolares, dessa forma há uma tendência a se adequar às necessidades da escola. Posto isso, a autora entende como promissor a interação entre o museu e a escola se a intenção do professor com a visita ao museu for, além da contextualização dos conceitos científicos trabalhados em sala de aula, a ampliação cultural de seus alunos.

Portanto, entendemos que qualquer ação educacional só terá impacto positivo na formação dos estudantes se os professores estiverem devidamente envolvidos com o processo e claramente conscientes do seu papel neste trabalho.

A esse respeito, Abib et.al (2012) defendem a importância dos espaços não-formais na formação do professor de ciências, propondo que além de se promover visitas, seminários e oficinas específicas para professores, os museus e centros de ciências deveriam ser melhor explorados pelos cursos de formação inicial de professores de modo que determinadas horas do estágio supervisionado fos- sem dedicadas à reflexão sobre os potenciais educativos desses espaços.

Assim sendo, neste trabalho, buscamos fazer um levantamento das ideias que professores de Física, da rede estadual de ensino de uma cidade da região do Vale do Paraíba - interior do Estado de São Paulo, têm dos museus e centros de ciências e dos impactos que visitas de alunos a essas instituições podem trazer para a aprendizagem de conceitos científicos. Além disso, buscamos conhecer como pensam esses professores sobre uma possível interação entre os museus e centros de ciências com as escolas de educação formal.

\section{A Pesquisa}

Nossa pesquisa constituiu-se de um levantamento com os professores a partir da aplicação de um questionário estruturado e aberto com questões estabelecidas em três dimensões de análise:

A primeira, visando obter informações sobre o perfil dos professores participantes, com vistas a uma melhor caracterização dos sujeitos de pesquisa;

A segunda, com o intuito de fazer um levantamento das ideias que os professores fazem do papel que as visitas à museus e centros de Ciências exercem sobre a aprendizagem de seus alunos; e

A terceira, com vistas a identificar como os professores veem uma interação entre os museus e centros de Ciências e as escolas de educação formal.

O questionário, portanto, foi constituído como é mostrado no quadro a seguir:

Tabela 1 - Questionário aplicado aos professores

\begin{tabular}{c|c}
\hline Dimensões de análise & Informações solicitados no questionário \\
\hline $\begin{array}{c}\text { 1a - Caracterização do } \\
\text { perfil dos sujeitos da } \\
\text { pesquisa }\end{array}$ & -Qual o nome? \\
-Qual a idade? & -Qual o ano e área de formação? \\
& -Fez pós-graduação? Em que área? \\
-Qual o número de turmas que possui? \\
-Qual sua carga horária semanal? \\
-Quanto tempo tem de serviço?
\end{tabular}


Esse questionário foi enviado para todos os professores de física ligados à Diretoria de Ensino da cidade de Guaratinguetá no interior de São Paulo, ou seja, 17 docentes no total. Contudo, só obtivemos o retorno de 10 questionários respondidos.

Os dados obtidos foram analisados de acordo com a metodologia de análise de conteúdo sob a perspectiva de Bardin (1977). Julgamos esse método de análise mais adequado ao nosso objeto de estudo e mais coerente com os objetivos fixados. De acordo com Oliveira et al. (2003, p. 6), o método de análise de conteúdo é apropriado para a pesquisa quando se obtém dados oriundos de entrevistas ou questionários, pois proporciona ao pesquisador maior controle sobre suas perspectivas e sua subjetividade devido a delimitação categórica.

O procedimento consistiu-se na identificação de categorias presentes nas respostas dadas pelos professores de acordo com o tema levantado. Posteriormente, as respostas foram agrupadas e analisadas de acordo com as categorias identificadas.

\section{Resultados e análises}

Com relação ao perfil dos professores participantes podemos sintetizar os dados obtidos a partir do quadro 2 a seguir:
Por esses dados podemos verificar que os professores de física que participaram de nossa pesquisa, têm experiência profissional significativa, em média de 16 anos de atuação em sala de aula. Apresentam formação acadêmica na área da disciplina em questão, com exceção de apenas um professor que é formado em matemática e tecnologia de processamento de dados, todos os demais docentes são Licenciados em física. Sete professores cursaram ou estão cursando pós-graduação.

Com relação à dimensão de análise relativa a como esses professores veem o papel dos museus e centros de ciências para a aprendizagem de conceitos científicos, todos os docentes concordam com a importância dessas instituições.

Pedimos para que os professores descrevessem sua concepção sobre "ensinar ciência". Cinco professores relacionaram o ensino de ciências com o desenvolvimento de habilidades que se espera de um cidadão cientificamente alfabetizado, como por exemplo, observar e entender os fenômenos que o sujeito vivencia em seu cotidiano. Podemos observar um exemplo na resposta do Professor 1 :

“Descrever, demostrar os fenômenos naturais, físicos e químicos que ocorrem. Desenvolver um pensamento crítico e social sobre o mundo em que vivemos." (Prof.1)

Os demais professores relacionaram o ensino de ci-

Tabela 2 - Perfil dos participantes da pesquisa

\begin{tabular}{c|c|c|c|c|c}
\hline & $\begin{array}{c}\text { Idade } \\
\text { (Anos) }\end{array}$ & Formação Acadêmica & $\begin{array}{c}\text { Tempo de } \\
\text { formação }\end{array}$ & $\begin{array}{c}\text { Tempo de } \\
\text { serviço }\end{array}$ & Pós Graduação \\
\hline Prof.1 & 41 & $\begin{array}{c}\text { Licenciatura em física } \\
\text { Licenciatura em Pedagogia }\end{array}$ & 15 & 15 & $\begin{array}{c}\text { Mestrado - Física de } \\
\text { Plasma }\end{array}$ \\
\hline Prof.2 & 55 & Licenciatura em física & 30 & 30 & Não possui \\
\hline Prof.3 & 51 & $\begin{array}{c}\text { Engenharia Elétrica } \\
\text { Licenciatura em Física } \\
\text { Licenciatura em Pedagogia }\end{array}$ & 17 & 17 & $\begin{array}{c}\text { Mestrado - Física de } \\
\text { Plasma }\end{array}$ \\
\hline Prof.5 & 52 & $\begin{array}{c}\text { Licenciatura em Física } \\
\text { Matemática e Tecnólogo em } \\
\text { Processamento de Dados }\end{array}$ & 32 & 18 & $\begin{array}{c}\text { Mestrado - Projetos } \\
\text { educacionais } \\
\text { (cursando) }\end{array}$ \\
\hline Prof.6 & 31 & $\begin{array}{c}\text { Licenciatura em Física } \\
\text { Computação e } \\
\text { Pedagogia }\end{array}$ \\
\hline Prof.7 & 49 & $\begin{array}{c}\text { Engenharia Mecânica } \\
\text { Licenciatura em Física } \\
\text { Pedagogia }\end{array}$ & 22 & 11 & $\begin{array}{c}\text { Mestrado - Ensino de } \\
\text { Ciências }\end{array}$ \\
\hline Prof.8 & 26 & $\begin{array}{c}\text { Licenciatura em Física } \\
\text { Prof.9 }\end{array}$ & 58 & $\begin{array}{c}\text { Licenciatura em Física } \\
\text { Gestão em }\end{array}$ \\
\hline Prof.10 & 36 & $\begin{array}{c}\text { Licenciatura em Física } \\
\text { Pós graduac̃a em }\end{array}$ & 11 & 11 & $\begin{array}{c}\text { Mestrado - Ensino de } \\
\text { Ciências (cursando) }\end{array}$ \\
\hline
\end{tabular}


ências à motivação para que os alunos prossigam nos estudos visando a uma formação futura na área científica.

“Ensinar ciências é motivar jovens a buscar conhecimentos nas áreas abordadas por esse campo de estudo, tanto para a vida quanto para uma possível escolha da carreira profissional." (Prof.2)

Em seguida, perguntamos aos professores qual era, na visão deles, o papel das atividades experimentais no Ensino de Física. Cinco professores destacam a importância de ocorrerem, porém não sabem explicar o porquê.

"Fundamental para aumentar o conhecimento em ciências" (prof. 2)

“Sem dúvida é o caminho para que o aluno se aproprie dos conteúdos de Física, Química e Biologia tendo como suporte os modelos matemáticos. " (Prof. 3)

Três professores do grupo acreditam que a experimentação contribui para ensino no aspecto da motivação, como afirma o professor 7:

“As atividades experimentais são importantíssimas para despertar o gosto e a busca pelo conteúdo cientifico nos alunos." (Prof.7)

Apenas um dos professores apontou que a atividade experimental é um excelente recurso para ensinar ciências, no entanto ressalta que deve haver alguns cuidados e uma certa preparação por parte do professor.

"A atividade experimental tem um papel importante, porém apenas a atividade experimental sem uma explicação do professor não garante que os alunos entenderam a proposta da atividade experimental." (Prof.8)

Apesar de todos destacarem a relevância da atividade experimental, quando perguntados sobre a frequência da utilização de atividades experimentais em sala de aula, metade do grupo de professores disseram que realizam tais atividades numa frequência de uma ou duas por bimestre, e a outra metade disse que raramente ou nunca a utilizam, apontando vários motivos como à falta de tempo, a escassez de materiais, inexistência de espaço adequado no ambiente escolar e, em alguns casos, a falta de tempo para a preparação, planejamento e desenvolvimento didático desse tipo de atividade.

“Utilizo atividades experimentais em sala de aula com pouca frequência, cerca de uma atividade por bimestre ou menos que isso, no caso de algumas turmas. Gostaria de fazer uso com maior frequência, mas questões relacionadas, principalmente, ao tempo e ao material têm dificultado que isso ocorra." (Prof.6)
Essas afirmações estão de acordo com o que defendem Gaspar (1993) e Vieira et.al (2005), sobre a vantagem do museu de ciências em proporcionar aos indivíduos vivências que a escola não pode proporcionar.

Ao serem perguntados mais especificamente sobre a frequência e o papel da visitação a museus e centros de ciências, a maioria dos professores, oito dos dez participantes, afirmaram não ter o costume de levar seus alunos a centros de ciências e o motivo predominante foi a falta de verba e de transporte.

Na sequência os professores foram questionados sobre a possibilidade de aprendizagem nos museus de ciências, se é possível ensinar e aprender nesses espaços. Três dos dez professores afirmaram que uma visita a um museu ou centro de ciências serve tanto para promover a aprendizagem quanto à motivação, porém não justificaram os motivos pelos quais acreditam nisso.

"Sem dúvida pode e aprende-se nos Centos de Ciência além de despertar o interesse pela Área de Ciências e Engenharia" (Prof. 3)

"As duas coisas" (Prof. 9)

"Serve para os dois fins" (Prof. 10)

Se o aprendizado destacado pelos professores for entendido como a capacidade de não só compreender conceitos, como de descrever os fenômenos naturais e se posicionar criticamente em relação a eles, há uma clara supervalorização do papel dos museus e centros de ciências.

Nesse aspecto, esses professores atribuem aos museus de ciências aprendizagens que só serão, de fato, efetivados no ensino formal. É claro que os museus realizam demonstrações de fenômenos e, as contribuições dos monitores oferecem ao visitante uma razoável descrição do fenômeno demonstrado, contudo não se pode esperar que somente essa simples abordagem, por mais bem feita que seja, possa efetivar compreensões de conceitos, leis, princípios e métodos que permitam ao aluno o desenvolvimento do pensamento crítico.

Pode-se admitir que ideias e reflexões realizadas nas diferentes interações desencadeadas nos museus e centros de ciências suscitem discussões mais aprofundadas no contexto de sala de aula, possibilitando, dessa forma, o desenvolvimento da competência crítica, destacada pelo professor em sua fala.

Assim sendo, se o professor se der por satisfeito com a visita ao museu de ciências, esperando que tais habilidades sejam, somente nestas abordagens, desenvolvidas, então as visitas não serão tão efetivas quanto podem ser.

Por outro lado, cinco professores do grupo acreditam no potencial de aprendizagem dos museus de ciências, mas, ao justificarem suas respostas, acabam por destacar a motivação que esses espaços proporcionam para que a aprendizagem ocorra de fato em sala de aula. Percebemos 
essa categoria de resposta na fala do professor 8:

“É possível aprender, porém despertar o interesse pela ciência é meu maior objetivo, aluno motivado aprende melhor." (Prof.8)

Esse tipo de concepção sugere que o professor espera das instituições de educação não formal vivências que poderão ser aproveitadas na escola. Mesmo que não se referindo à retomada em sala de aula dos conceitos informalmente discutidos nos museus e centros de ciências, o docente manifesta a expectativa de que os alunos voltem para a sala de aula mais interessados e motivados na aprendizagem de conceitos científicos.

Esse tipo de expectativa também se mostra um tanto ingênua, já que não há manifestação de qualquer intenção em se promover uma maior interação entre o que foi visto e discutido nos museus e centros de ciências com o que está ou será abordado em sala de aula.

Assim sendo, nada garante que a motivação e o entretenimento promovido nos museus e centros de ciências se manterão no ambiente escolar.

Outro professor destacou a expectativa de realizar suas aulas no centro de ciências:

“Acredito ser possível ensinar e aprender Ciência nesses centros, ainda que muitas vezes seja explorado mais o caráter lúdico que eles oferecem. A partir da parceria entre o professor e os responsáveis pelos centros, pode-se preparar uma aula ou mesmo adaptá-la para que seja realizada no centro em vez da sala de aula" (prof. 6)

Mais uma vez vemos um exemplo das afirmações feitas tanto por Gaspar (1993) quanto por Vieira et.al (2005), sobre a (des)instrumentalização das escolas para a realização de atividades práticas experimentais e de demonstração experimental.

Acerca desse posicionamento fica a preocupação de Lopes (1991) e de Marandino (2001) com o que chamaram de a escolarização dos museus e centros de ciências. Nesse caso, poderia haver um desvio do papel e da missão das instituições de educação não-formal.

Em outro questionário respondido um professor se manifesta alertando para o fato de que a aprendizagem nos espaços de educação não-formal só ocorrerá, de fato, se as atividades desenvolvidas forem bem planejadas e bem articuladas com as atividades realizadas na escola.

“Sim, acho que é possível desde que haja um planejamento adequado. Os alunos devem estar preparados para a visita, ou seja, devem saber exatamente o que observar para que depois possa haver uma discussão produtiva em sala de aula sobre os experimentos vistos. Acredito que deve haver relação entre as atividades experimentais do Centro de Ciências e o conteúdo teórico estudado em sala." (Prof.4)

A respeito de como esses professores pensam a in- teração entre as instituições de ensino não formal com as escolas de educação formal, pudemos observar que a maioria dos professores, seis deles, acreditam que as visitas a museus e centros de ciências podem contribuir de fato para o ensino, porém não especificaram como poderia ser realizada, metodologicamente, a aproximação do museu com a escola.

A ideia manifestada pelo professor 4, em sua resposta ao questionário, evidencia um bom exemplo de interação entre museu de ciência e a escola. Contudo, é preciso destacar que, dependendo do tipo de atividade proposta aos alunos a ser realizada na visitação, como por exemplo, anotar dados, preencher relatórios, pode impor afazeres que minimiza ou mesmo impede o caráter lúdico da visita.

Apenas um professor apresentou descrença na funcionalidade de uma possível proposta de aproximação do museu com a escola, alegando muitas dificuldades na realização de atividades dessa natureza.

"Isso não é fácil, o papel aceita tudo, mas dentro da sala de aula é outra coisa." (Prof.9)

Nem sempre é fácil para o professor se envolver em atividades diferenciadas das práticas costumeiramente por ele realizadas, tendo em vista a falta de tempo, o excessivo número de aulas, bem como devido ao desencantamento que muitas apresentam com propostas inovadoras. Além disso, de fato, a articulação entre os museus de ciências e as escolas precisa ser bem pensada para que o papel de cada uma das instituições possa ser bem desempenhado.

Nesse aspecto, acreditamos ser válida da proposta de Abib et.al (2012) sobre a importância de se considerar nos espaços não formais de educação a formação de professores. Essa iniciativa poderia ser um caminho interessante para que a interação entre a escola e os museus se fizesse mais naturalmente.

Por fim, sobre a disposição dos docentes em participarem de uma ação que tenha como objetivo a aproximação do museu de ciências com a escola e quais seriam as dificuldades que possivelmente encontrariam para realizá-la, apenas um professor se posicionou de forma negativa, afirmando que não estaria disposto a participar eventualmente de uma ação como esta devido às burocracias, falta de tempo e de recursos. Em contrapartida, todos os outros professores participantes afirmaram ter disposição para participar de ações desse tipo. No entanto, cinco deles afirmaram que a falta de verba e transporte seria um empecilho; os demais não apontaram nenhuma dificuldade.

\section{Conclusões}

A partir das respostas obtidas, observamos que os professores entendem a importância de se buscar alternativas para o ensino de conceitos científicos, como por exemplo, as atividades experimentais, porém, alguns obstáculos 
dificultam a utilização deste artifício. Este fato corrobora a opinião de diversos autores quanto à importância dos museus de ciências na educação no sentido de que esse tipo de instituição pode proporcionar aos seus visitantes experiências e vivências que a escola, por muitas vezes, não pode proporcionar.

Quanto aos museus e centros de ciências, os professores reconhecem a importância destes espaços para o ensino de ciências e se mostraram dispostos a participar de ações que visam o estabelecimento de uma parceria entre o espaço de ensino não formal com a escola. Porém, a grande maioria dos participantes da pesquisa não especificou como poderia se estabelecer, metodologicamente, essa parceria. Isso remete à importância da inclusão dos museus e centros de ciências na formação inicial e continuada de professores.

Concluímos que a proposta de uma ação como essa deve levar em conta, não somente os cuidados para se evitar a escolarização dos museus de ciências, mas também as dificuldades apontadas pelos professores, bem como a falta de tempo e recursos, de modo que a ação a ser desenvolvida seja coerente com a situação da realidade do professor, a qual ocasionalmente pode impedi-lo de participar de ações preparatórias oferecias pelos museus devido a localização e a falta de recursos.

Sendo assim, julgamos que pensar em uma proposta em que o professor possa trabalhar de maneira mais independente no planejamento de uma atividade que promova a parceria entre o ensino formal e o não formal, respeitando as particularidades de cada um dos espaços em que essas modalidades de ensino ocorrem, possa ser uma alternativa benéfica para o processo de ensino e de aprendizagem de ciências.

\section{Referências}

ABIB, M.L.V.S. et al. Os espaços não formais e sua relação com a formação de professores no contexto brasileiro. XVI ENDIPE - Encontro Nacional de Didática e Práticas de Ensino - UNICAMP - Campinas-2012. Disponível em: http://www. infoteca.inf.br/endipe/smarty/templates/arquivos_template/ upload_arquivos/acervo/docs/3183p.pdf. Acesso em 01 de mar de 2016.

ALMEIDA, A. M. Desafios da relação Museu-Escola. Comunicação e Educação, v.10, p.50-53, set/dez, 1997.

BARDIN, L. Análise de conteúdo. Lisboa: Edições 70; 1977.

CHAMPAGNE, D. W. The Ontario Science Center in Toronto: Some impressions and some questions. Educational Technology, 15(8), 36-39, 1975.

FARA, P. Understanding science museums. Museums Journal, 94(12), 25, 1994.
GASPAR, A. Museus e centros de ciências: conceituação e proposta de um referencial teórico. 1993. 173f. Tese (Doutorado em Educação) - Faculdade de Educação, Universidade de são Paulo -SP.

GOHN, M. G. Educação não formal e o educador social: atuação no desenvolvimento de projetos. São Paulo: Cortez,2010.

LOPES, M. M. A favor da desescolarização dos museus. Educação e Sociedade. N. 40, p. 443 - 455, 1991.

MARANDINO, M. Interfaces da relação museu-escola. Caderno Catarinense de Ensino de Física. v. 18, n. 1, p. 85 $-100,2001$.

OLIVEIRA, E. et al. Análise de conteúdo e pesquisa na área da educação. Revista diálogo educacional. Curitiba, v. 4, n. 9, p. $11-27$, mai./ago. 2003.

PARKYN, M. Scientific imaging. Museums Journal, 93(10), 29-34, 1993.

RAVEST, J. Where is the science in science centres? ECSITE Newsletter, Summer, 10-11, 1993.

RENNIE, L. J.; WILLIAMS, G.F. Science Centers and Scientific Literacy: Promoting a Relationship with Science. Science Education. V. 86, n. 5, pp. 706-726, September 2002.

SANTOS, D.A. Um estudo sobre o impacto causado pela interação museu-escola na relação professor-aluno nas aulas de física. 2015. 136f. Dissertação de Mestrado. Universidade Federal de Itajubá. Itajubá. 2015.

SCHALL, V.T. Pedagogia e Didática/Pesquisa e Avaliação. Em: Guimarães, V. e Silva, G.A. (Coords.). Implantação de Centros e Museus de Ciências. Rio de Janeiro: Editora da UFRJ, 313-318, 2002.

SHORTLAND, M. No business like show business. Nature, 328, 213-214, 1987.

VALENTE, M.E; CAZELLI, S. E ALVES F. Museus, ciência e educação: novos desafios. Rev. História, Ciência, SaúdeManguinhos, 12 (supl.), 183-203, 2005.

VIEIRA, V.et al. Espaços não - formais de ensino e o currículo de ciências. Ciência e Cultura, v.57, n.4, p.21-33, out./dez. 2005.

VOGT, C. De ciências, divulgação, futebol e bem-estar cultural. PORTO, C.; BROJAS, A.M; BORTOLIERO, S.T. Orgs. Diálogos entre ciência e divulgação científica. Salvador: EDUFBA, 2011.

WYMER, P. Never mind the science, feel the experience. New Scientist, 5 October, 49, 1991. 